\title{
Numerical Investigation of the Seismic Behavior of Unanchored Steel Tanks with an emphasis on the Uplift Phenomenon
}

\author{
Jalal Akbari* \\ Bu-Ali Sina University, Department of Civil Engineering, Hamedan, Iran \\ j.akbari@basu.ac.ir, bttps://orcid.org/0000-0001-9713-8652
}

\section{Omid Salami}

Laboratory of Earthquake Engineering and Structural Health Monitoring of Infrastructures (LEESHMI), Bu-Ali Sina University, Hamedan, Iran

omidsalami@gmail.com

\author{
Mohsen Isari \\ Faculty of Civil Engineering, University of Tabriz, Tabriæ, Iran \\ isarimobsen@tabrizu.ac.ir
}

\begin{abstract}
Ground steel storage tanks are widely used in different industries. Regarding the significance of these structures, ensuring the proper performance of such structures in earthquakes needs evaluating their seismic performance. The present study examines the seismic behavior of an unanchored fluid storage system via ABAQUS after validation with an experimental model. Next, the uplift of the bottom sheet is studied using the accelerogram records of the $1940 \mathrm{El}$ Centro and 1994 Northridge earthquakes. The overturning moment time history of the fluid storage system and the maximum overturning moments were obtained to identify their behavior. The results indicated that not bracing storage tanks leads to the uplift phenomenon. Finally, the maximum axial stress of the storage tank shell was compared with the values recommended in the design codes to control the buckling.
\end{abstract}

KEYWORDS. Liquid storage tanks; Steel cylindrical tanks; Unanchored steel tanks; Water storage tanks; Uplift of steel tanks.

\section{open Access}

Citation: Akbari, J., Salami, O., Isari, M., Numerical Investigation of the Seismic Behavior of Unanchored Steel Tanks with an emphasis on the Uplift Phenomenon, Frattura ed Integrità Strutturale, 53 (2020) 92-105.

Received: 20.01 .2020

Accepted: 21.03 .2020

Published: 01.07.2020

Copyright: (C) 2020 This is an open access article under the terms of the CC-BY 4.0, which permits unrestricted use, distribution, and reproduction in any medium, provided the original author and source are credited.

\section{INTRODUCTION}

ylindrical ground fluid storage tanks are widely used in different industries to store water, fuel and chemical materials. The failure of fuel tanks, particularly in oil refineries, can lead to large and uncontrollable fire and impose destructive environmental effects. Due to the presence of flammable materials in oil refineries, a small incident can 
lead to a large disaster that not only imposes financial and life losses but also imposes irreparable environmental damages whose effects can last for many years.

Comprehensive studies have been conducted on fluid storage tanks. Such studies are classified into three groups of analytical, experimental and numerical. Tank studies were mostly conducted in the late 1940s by Jacobsen [1] and in the early 1960s by Housner [2]. He investigated the dynamic fluid forces on the inner wall of a tank and its surrounding environment. They analytically proposed some graphs to derive the effective mass of the fluid and hydrodynamic forces for different length/diameter ratios of the tank. The effective mass later became an essential factor in obtaining the base shear of tanks. This method was used by engineers to design tanks until 1955. After the 1964 Alaska earthquake, an important study was conducted on the failure of tanks, which still is employed by Clough [3]. In the late 1970s, analytical studies were conducted on tanks by Veletsos, which demonstrated the more realistic behavior of tanks during earthquakes [4-8]. The validity of some of such models is accepted in the engineering society and included in design regulations as design standards. However, some tanks designed based on new regulations are damaged in intensive earthquakes. The weak performance of tanks in earthquakes indicates that the seismic behavior of such tanks is more complicated than that assumed in analytical or even numerical models and regulations. Thus, considering the inability of analytical relations and complications, several experimental studies were conducted on the seismic behavior of tanks along with analytical and numerical methods. For example, Niwa [9-10], and Manos et al. [11] experimentally studied unanchored tanks. They examined scaled models under dynamic and static loads on shaking tables. They employed different conditions in the bottom clamping, support rigidity, the length/radius ratio of the tank and tank top shapes and compared the obtained results. Zui et al. [12] investigated the clamping effect of an unanchored cylindrical tank on its seismic behavior. They concluded that the clamping of the tank considerably changed the seismic response. Barton et al. [13] derived the seismic responses of fluid storage tanks to horizontal earthquakes via the added mass method Chiba [14-15] evaluated the nonlinear vibration of cantilevered cylindrical tanks, including two polyethylene tanks. They found that the nonlinearity of a tank's behavior is dependent on the heights of the tank and fluid.

The general results of experimental studies suggest that the uplift mechanism, which is nonlinear to the excitation frequency, is an important phenomenon in the seismic responses of unanchored tanks. Out-of-form wall deformation occurs in both anchored and unanchored seismic-loaded tanks. Such deformation and the uplift mechanisms change the stress distribution and lead to compressive stress on the tank wall. Such stress is larger in unanchored tanks than in anchored ones.

Owing to the rapid growth of computers, numerical techniques, particularly the finite element method (FEM), have widely been employed to evaluate the behavior of tanks with high accuracy. They employed anchored and unanchored tanks. ElZeiny [16] used the Eulerian-Lagrangian concept for the fluid and structure in their model. They obtained the nonlinear responses of fluid storage tanks by considering the waving of the water surface and the fluid-structure interaction (FSI). Their assumptions included unanchored cylindrical metal fluid storage tanks under the strong movement of the ground. Malhotra and Clough investigated the behavior of steel cylindrical tanks with a simple beam model [17]. As well, Malhotra studied the base uplifting phenomenon and simple seismic analysis of liquid-storage tanks [18-20]. Souli et al. [21] proposed a procedure known as the arbitrary Lagrangian-Eulerian (ALE) algorithm to solve the FSI problem. The ALE algorithm suggests that the grid and material are independent of each other and the grid topology is stable. This allows the fluid surface material to maintain its Lagrangian approach without becoming complicated due to large deformation, making it possible to deal with moving boundaries in grids.

Taniguchi [22] modeled and evaluated the dynamic movement parameters of unanchored cylindrical tanks containing a fluid in a single-direction movement. For FSI problems with large structural deformation and destructive fluid surface wave movements, Aquelt et al. [23] proposed a method based on trial and error to model the reaction of the structure with the Lagrangian approach and model the reaction of the fluid with the Eulerian approach. Virella et al. [24] predicted the maximum ground movement that would lead to elastic buckling on top of an anchored tank.

In the most important recent experimental study, Maekawa et al. [25] analyzed a model with a scale of 1:10 in terms of tank deformation and buckling. They reported that their method was properly consistent with experimental results in analyzing the bucking and behavior of a tank. Besides, they found that their method was sufficiently accurate in evaluating the seismic strength of tanks, such as seismic safety. Maekawa [26- 27] studied the seismic behavior of ground steel tanks via numerical modeling and obtained the reduction factor in regulations with higher accuracy.

The present study investigates the seismic behavior of unanchored steel tanks via time history analysis with a focus on the uplift mechanism. For this purpose, the relationships between hydrodynamic loads and the bottom sheet uplift and their effects on the structural deformation, structural stress, and fluid movement through the tank were explored. The following assumptions were used for numerical models.

- The physical properties of the tank material are linear.

- The fluid is incompressible and non-viscose. 
- The entire analyses are nonlinear and the time history analyses are an explicit integral.

- $\quad$ Adaptive meshing is used.

- FSI is incorporated.

- The interaction between the tank and its bottom support is ignored.

The fluid within the tank is generally assumed to be incompressible and non-viscous in the formulation of seismic problems for tanks. As well, the fluid is assumed to be non-rotational. The Laplace differential equation is employed based on the velocity potential function to model the ideal fluid movement. The Laplace boundary conditions are defined by the dynamic response of the tank structure. These boundary conditions are a combination of ground movement-induced vibration and hydrodynamic load-induced deformation.

\section{RESEARCH METHODOLOGY}

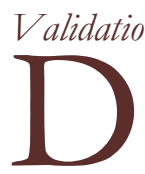

ue to the complications of the problem, it is required to validate the numerical model before examining the seismic behavior of the tank-fluid model. For this purpose, the study of Maykawa [25], which includes a roofless ground tank-fluid tank, was used. The experimental results included the measurement of the pressure, surface wave height, and shell stress in a time of $8 \mathrm{~s}$ by an accelerogram. As can be seen, the system (Fig. 1) is placed on a rigid rectangular plane.

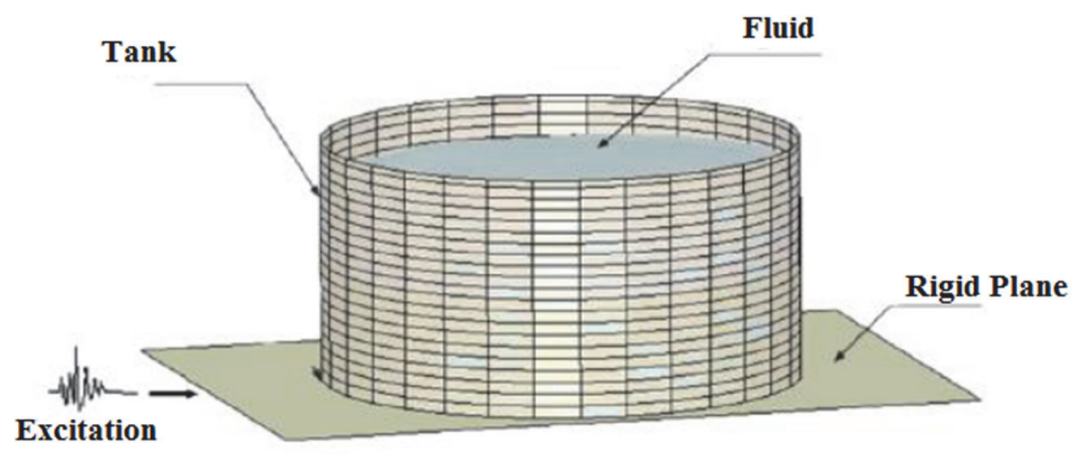

Figure 1: The physical model of the experimental tank-fluid system [14]

The tank's height and diameter are both $1.83 \mathrm{~m}$, the tank wall thickness is $2 \mathrm{~mm}$, the tank material is aluminum with an elasticity modulus of $71 \mathrm{GPa}$, the material density is $2,700 \mathrm{~kg} / \mathrm{m}^{3}$, and the yield stress is $100 \mathrm{MPa}$. The fluid is water with a density of $1,000 \mathrm{~kg} / \mathrm{m}^{3}$ in $1.53 \mathrm{~m}$ of height. The seismic load is applied by a seismic table with an accelerogram of maximum base acceleration of $0.5 \mathrm{~g}$. Fig. 2 demonstrates the acceleration records in the northsouth direction.

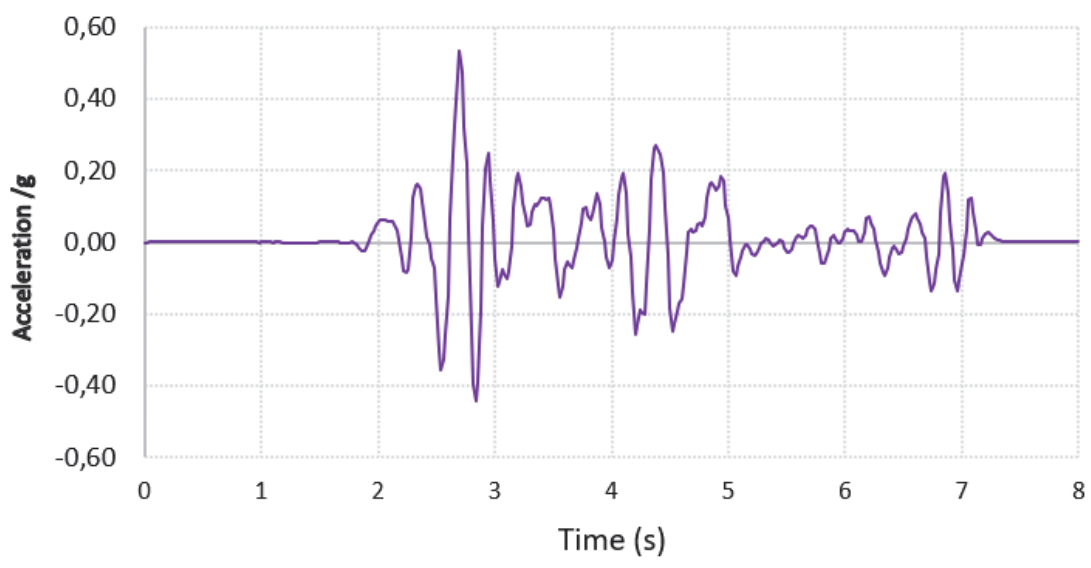

Figure 2: The accelerogram of the experimental model [14] 
Modeling was performed with finite-element software. The boundary conditions, loads, and other specifications used in the FEM model were the same as those employed in the experimental investigation. Double-curved membrane four-node elements with reduced integration and S4R membrane strain formulation (i.e., each element with four nodes and each node with six degrees of freedom) were employed in the tank wall meshing. These elements can properly simulate both local and general buckling. The modeling included the effects of large displacements and nonlinear shapes. Welding details were excluded from the model. Two separate components appear in water hydrodynamics: the impulsive component and the convective component. Here, the surface wave phenomenon plays a key role. Hence, specific eight-node elements of EOS type known as the C3D8R elements were employed. Such elements represent state equations and are used in software to model the states of surface waves. Typical fluid-structure interaction (FSI) specifications were used in the FSI problem. The FSI of penalty type with a factor of 0.015 was applied. Fig. 3 shows the time history results of pressure (except for the hydrostatic pressure) at two points in the tank with $\mathrm{r}=1.83 \mathrm{~m}$, height of $\mathrm{z}=0.05 \mathrm{~m}$ and $0.45 \mathrm{~m}$ from the bottom.
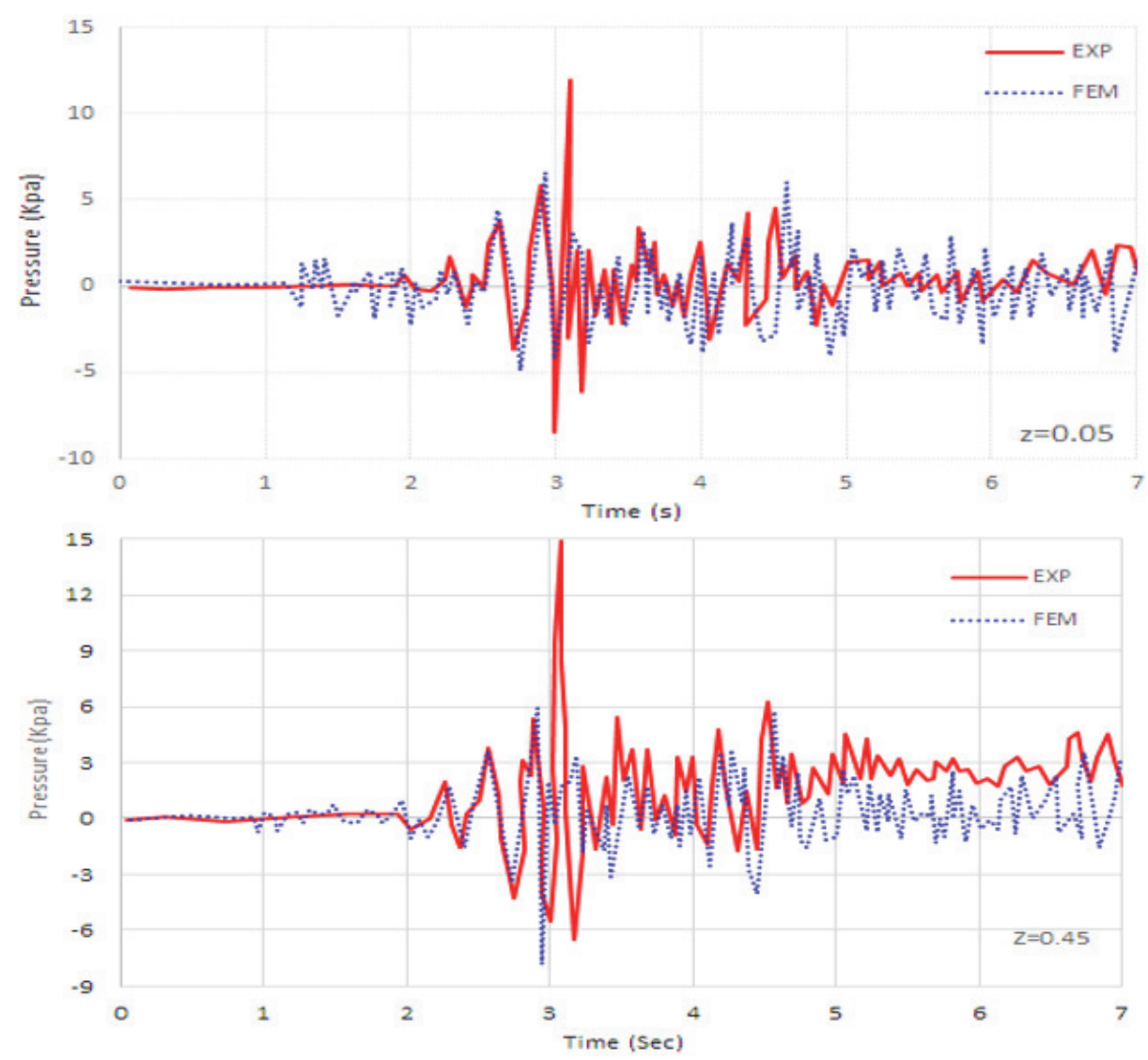

Figure 3: The time history of pressure at two points between experimental and numerical models

As can be seen, the numerical results are in good agreement with the experimental results. The pressure at $t=3 \mathrm{~s}$ indicates that the pressure response amplitude is affected by the bottom uplift. Fig. 4 represents the base shear time history. According to Fig. 4, both experimental and FEM results follow a similar trend in time. However, the FEM results are slightly larger.

The equivalent wave height is another essential aspect of tank-fluid systems. Here, the time history of the equivalent wave height is derived from numerical values. Fig. 5 depicts the equivalent time history responses at two points $\mathrm{r}=1.72 \mathrm{~m}$ and $\mathrm{r}=-1.72 \mathrm{~m}$. The points were selected on the loading axis. Although there are slight deviations from the experimental values in the numerical values, the numerical values are almost consistent with the experimental values in terms of peak times and wave shapes and amplitudes. 


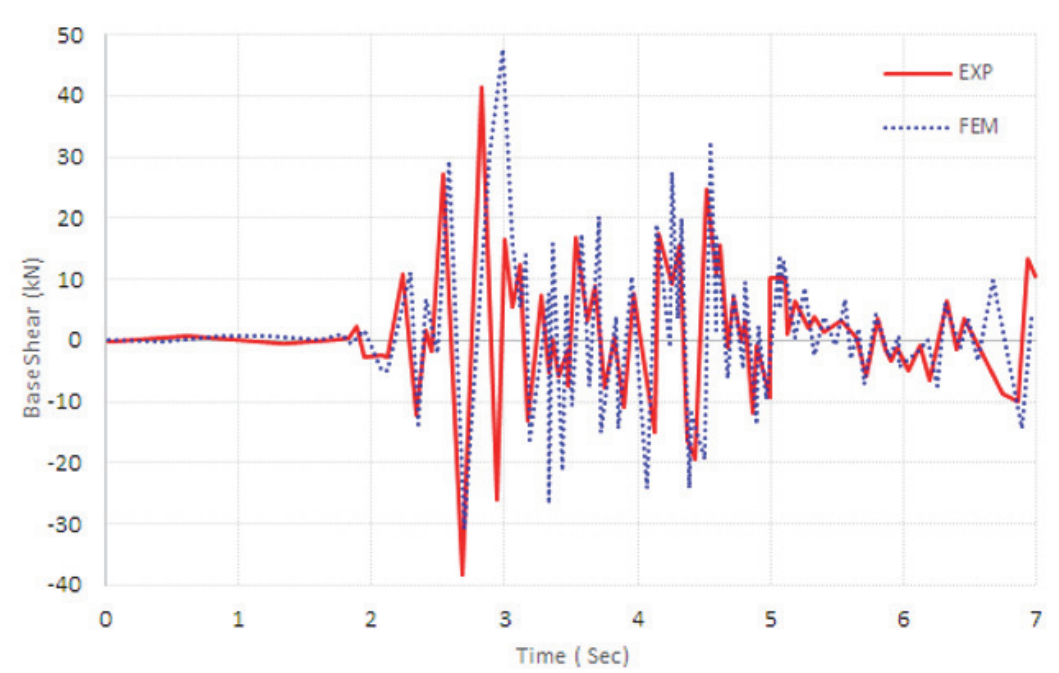

Figure 4: Base shear's time history between experimental and numerical models.
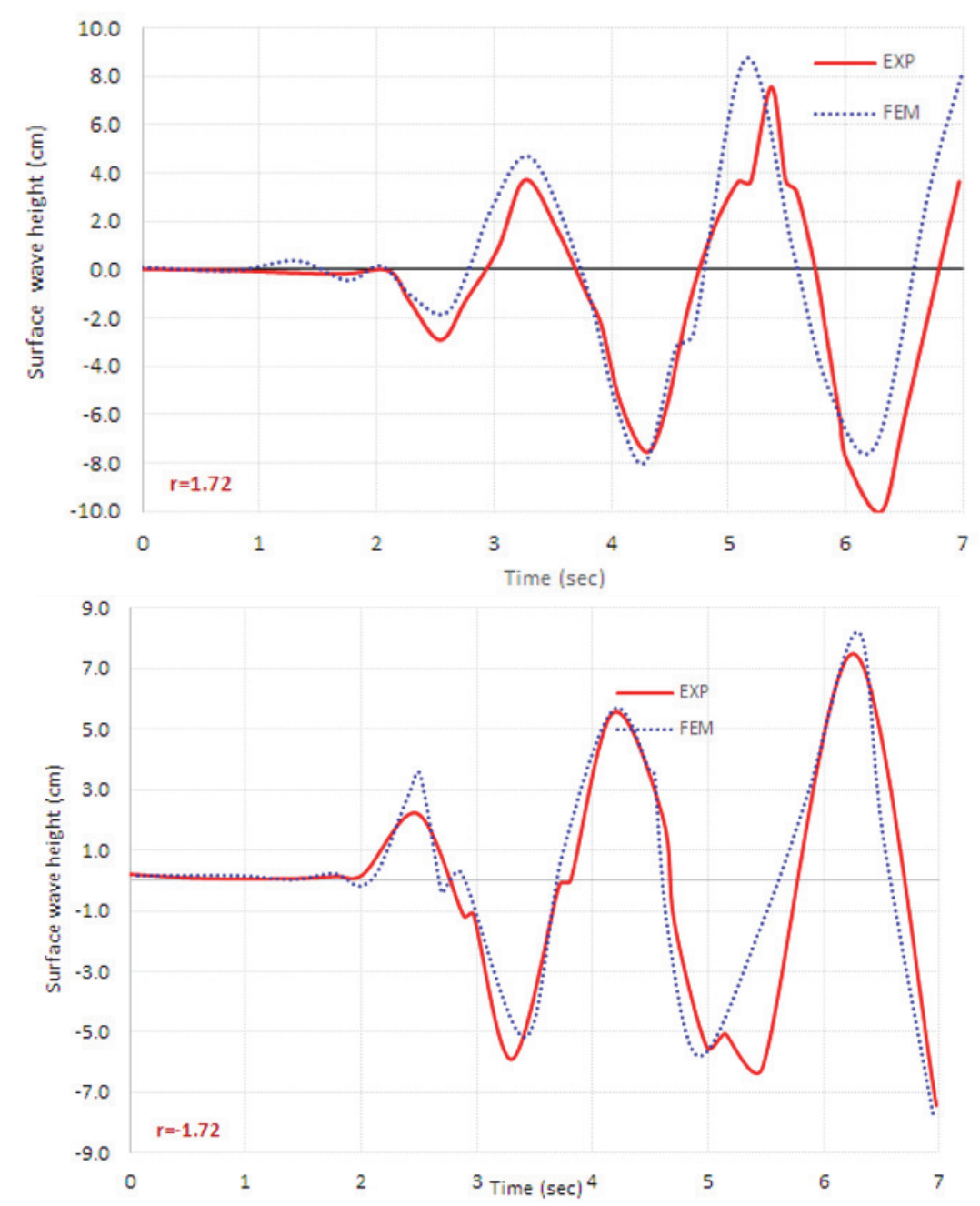

Figure 5: A comparison of the surface wave height time histories at points $\mathrm{r}=1.72 \mathrm{~m}$ and $\mathrm{r}=-1.72 \mathrm{~m}$

Tab. 1 summarizes the details and parametric features of the tank-fluid system, including the equivalent surface wave height, base shear, overturning moment and axial shell stress. 


\begin{tabular}{lcccccc}
\hline & Experiment & Numerical & $\begin{array}{c}\text { API } \\
\mathbf{( 6 5 0 )}\end{array}$ & $\begin{array}{c}\text { Euro code } \\
\mathbf{( 8 )}\end{array}$ & NZSEE & $\begin{array}{c}\text { Malhotra } \\
\text { et al. [19] }\end{array}$ \\
$\begin{array}{l}\text { Surface wave } \\
\text { height }(\mathrm{cm})\end{array}$ & 8.0 & 8.9 & 16 & 13 & 14 & 16 \\
$\begin{array}{l}\text { Base shear force } \\
(\mathrm{kN})\end{array}$ & 40.7 & 47.3 & 37.3 & 44.3 & 39.4 & 45.9 \\
$\begin{array}{l}\text { Overturning } \\
\text { moment }(\mathrm{kN} . \mathrm{m})\end{array}$ & 65.1 & 28.9 & 21.8 & 29.0 & 25.0 & 30.6 \\
$\begin{array}{l}\text { Axial shell stress } \\
(\mathrm{MPa})\end{array}$ & 25.8 & 20.5 & $\mathrm{~N} / \mathrm{A}$ & $\mathrm{N} / \mathrm{A}$ & 51.8 & $\mathrm{~N} / \mathrm{A}$ \\
\hline
\end{tabular}

Table 1: A comparison of responses between numerical and experimental methods and regulations codes

\section{NuMERICAL RESUlts}

$\mathrm{F}$ ig. 6 illustrates a schematic of the tank and its details. The unanchored roofless tank rests on a rigid bed. Tab. 2 provides the specifications of the material. The shell thickness varies at different heights. The fluid is water in the heights of 6,9 , and 12 , occupying $50 \%, 75 \%$, and $100 \%$ of the tank capacity, respectively. The Young modulus (E), Passion's index ( $(v)$, and density (e) of $210 \mathrm{GPa}, 0.3$, and $7800 \mathrm{~kg} / \mathrm{m}^{3}$ were applied to the tank material. Moreover, the density, bulk modulus, and wave speed of $1000 \mathrm{~kg} / \mathrm{m}^{3}, 2200 \mathrm{MPa}$, and $1449 \mathrm{~m} / \mathrm{s}$ were applied to the water, respectively.
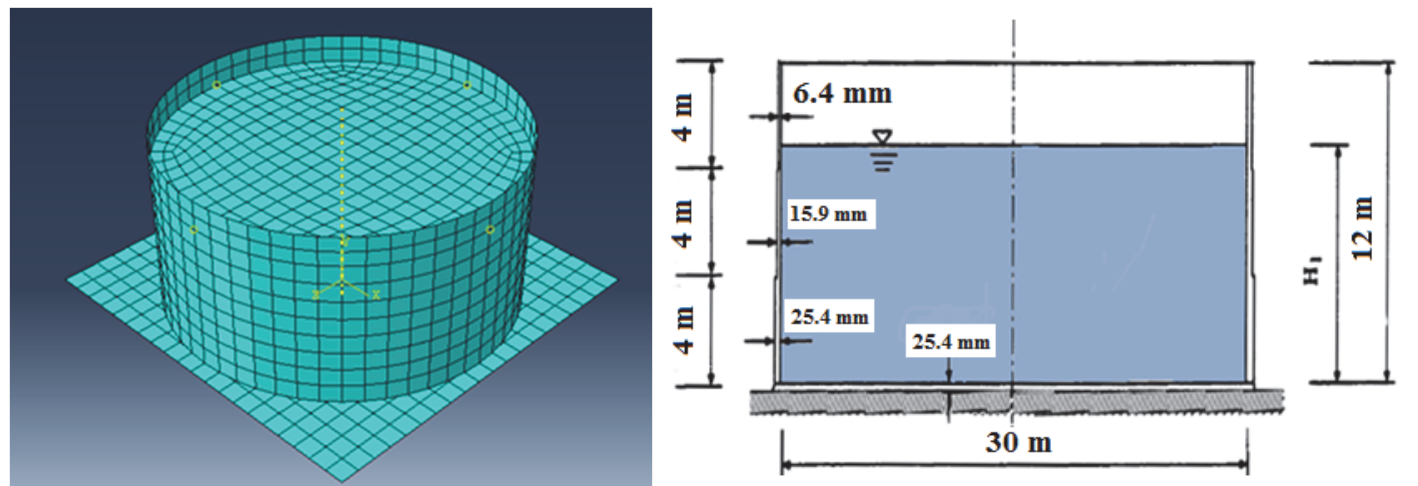

Figure 6: A schematic of the tank and the corresponding FEM mesh.

Six models with different fluid levels were incorporated. Tab. 2 provides the models.

\begin{tabular}{cccc}
\hline Model & $\begin{array}{c}\text { Fluid } \\
\text { Height (m) }\end{array}$ & $\begin{array}{c}\text { Occupied Tank } \\
\text { Capacity (\%) }\end{array}$ & Record \\
T1 & 6 & 50 & 1940 El Centro \\
T2 & 9 & 75 & 1940 El Centro \\
T3 & 12 & 100 & 1940 El Centro \\
T4 & 6 & 50 & 1994 Northridge \\
T5 & 9 & 75 & 1994 Northridge \\
T6 & 12 & 100 & 1994 Northridge \\
\hline
\end{tabular}

Table 2: The models and applied earthquake records for numerical studies 
Dynamic time history analyses were performed on the models at three different heights in a time of $12 \mathrm{~s}$ with the $1940 \mathrm{El}$ Centro and 1994 Northridge accelerogram records. Fig. 7 represents the specifications of the accelerogram records. The maximum ground accelerations of the El Centro and Northridge earthquakes occurred to be 0.35 and $0.58 \mathrm{~g}$ at 2.1 and 5.4 s, respectively, both in the north-south direction. [28]
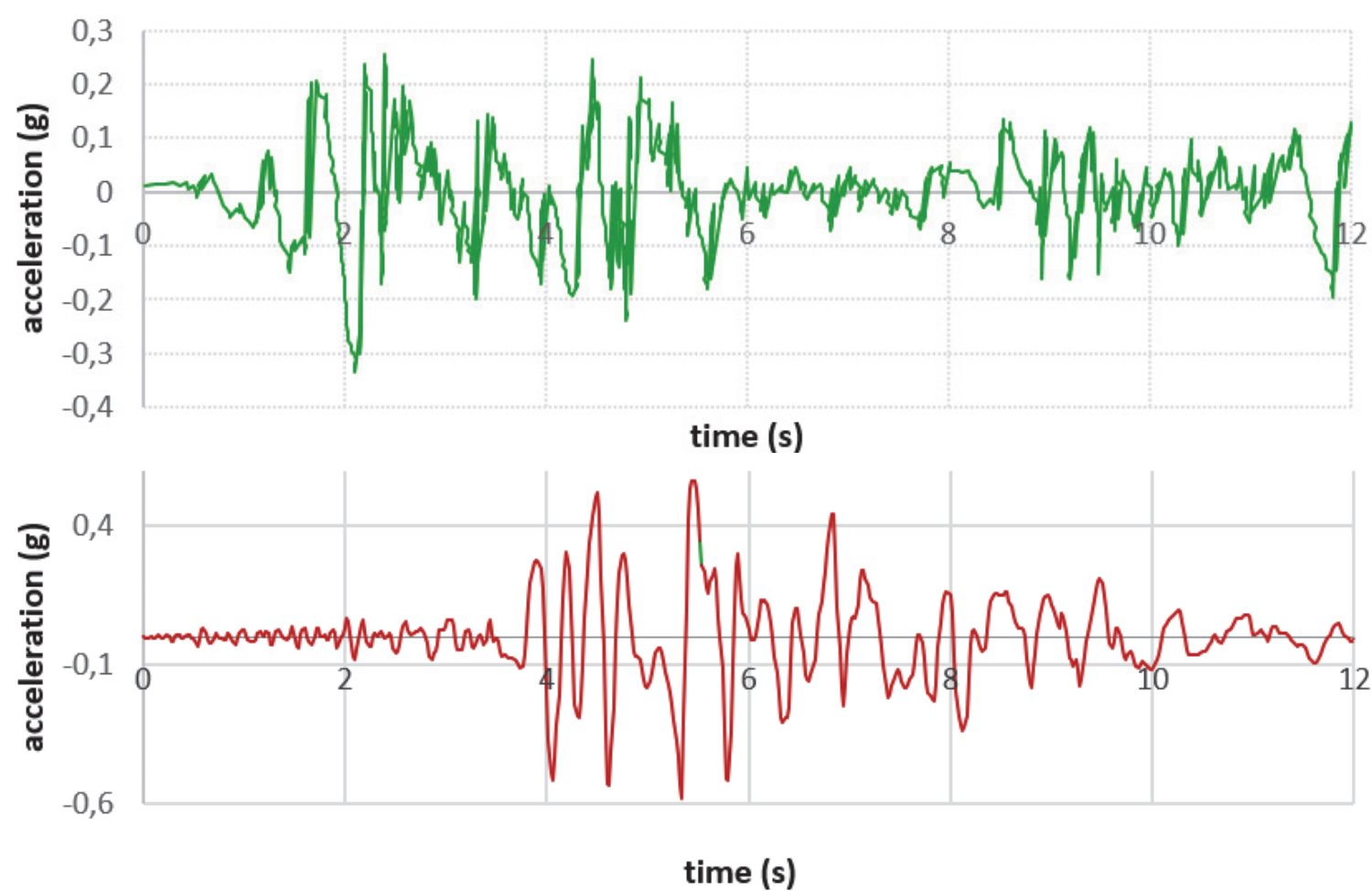

Figure 7: The accelerogram records of a) the El Centro (above), and b) the Northridge (below)

These analyses were performed to obtain a better insight into the behavior of unanchored fluid storage tanks under seismic loads. Figs. 8 and 9 indicate the overturning moment time histories of the tank-fluid system for the Northridge and El Centro earthquakes, respectively. The first reaction occurred from the beginning for approximately 5 and $4.5 \mathrm{~s}$ (Figs. 8 and 9, respectively) when the system was subject to the El Centro and Northridge earthquakes. In this time, the load mostly arose from impulsive modes.

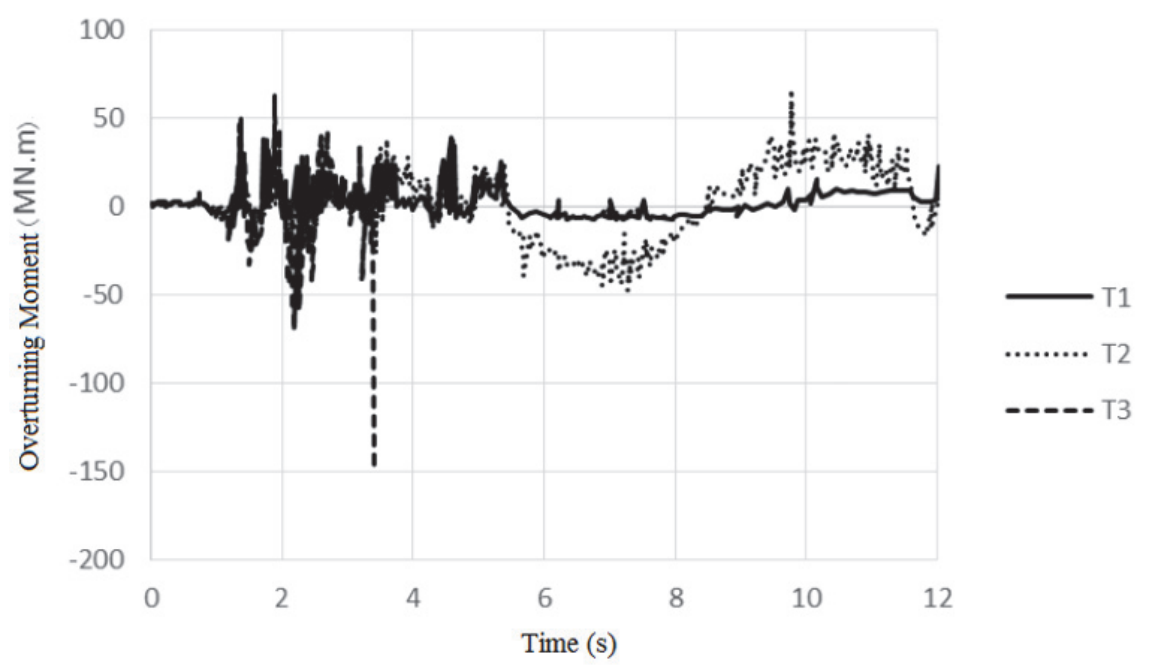

Figure 8: The overturning moment under the 1940 El Centro earthquake. 


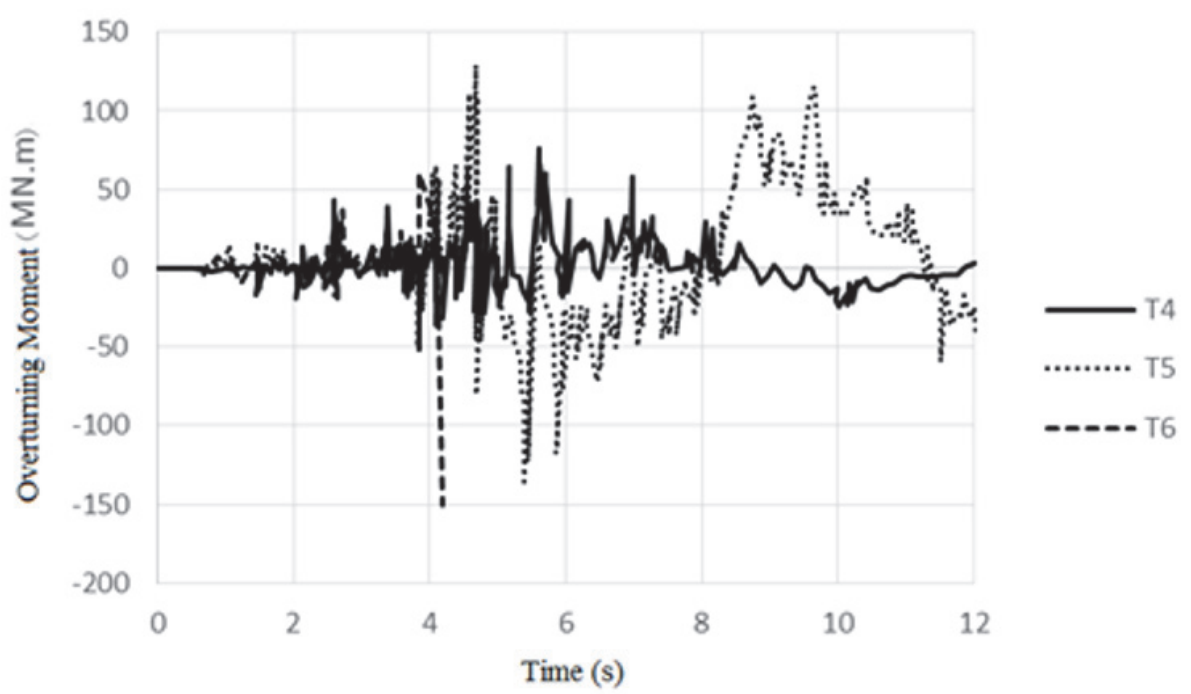

Figure 9: The overturning moment under the 1994 Northridge earthquake

As can be seen, the second part of the graphs resulted from high-period movements. The fluid pressure loads on the wall were calculated, and their reflection caused the fluid to move within the tank. The observed behavior of lateral loads revealed that the behavior of the fluid was initially induced by impulsive values and then by convective values. Tab. 3 provides the numerical results at the maximum load and the corresponding accelerogram record.

\begin{tabular}{|c|c|c|c|c|c|}
\hline Earthquake & Tank & $\begin{array}{l}\text { Maximum Load Units } \\
\text { (MN, MN.m) }\end{array}$ & & Time (s) & Acceleration (g) \\
\hline 1940 El Centro & $\mathrm{T} 1$ & $\begin{array}{c}\text { Lateral Load } \\
\text { Overturning Moment }\end{array}$ & $\begin{array}{l}11.46 \\
28.29\end{array}$ & 4.51 & 0.21 \\
\hline 1940 El Centro & $\mathrm{T} 2$ & $\begin{array}{c}\text { Lateral Load } \\
\text { Overturning Moment }\end{array}$ & $\begin{array}{l}16.62 \\
69.09\end{array}$ & 9.73 & 0.04 \\
\hline 1940 El Centro & T3 & $\begin{array}{c}\text { Lateral Load } \\
\text { Overturning Moment }\end{array}$ & $\begin{array}{c}74.81 \\
388.40\end{array}$ & 3.52 & 0.11 \\
\hline 1994 Northridge & $\mathrm{T} 4$ & $\begin{array}{c}\text { Lateral Load } \\
\text { Overturning Moment }\end{array}$ & $\begin{array}{l}14.11 \\
36.51\end{array}$ & 5.44 & 0.53 \\
\hline 1994 Northridge & T5 & $\begin{array}{c}\text { Lateral Load } \\
\text { Overturning Moment }\end{array}$ & $\begin{array}{c}29.28 \\
130.50\end{array}$ & 5.36 & 0.47 \\
\hline 1994 Northridge & T6 & $\begin{array}{c}\text { Lateral Load } \\
\text { Overturning Moment }\end{array}$ & $\begin{array}{c}54.49 \\
278.10\end{array}$ & 4.11 & 0.51 \\
\hline
\end{tabular}

Table 3: The obtained results from applied earthquake records.

As can be seen, the maximum loads did not occur at the time of the maximum acceleration. A comparison of the earthquake time histories and input accelerogram records with the load time histories reveals three different behaviors in the response time histories:

1. The maximum load occurs when the ground movement is large. For example, T6 overturned at $4.11 \mathrm{~s}$ with a ground acceleration of above $0.5 \mathrm{~g}$.

2. The maximum load happens when the total of the impulsive and vibrating movements of the fluid is maximum. For example, the maximum load of T2 happened at $9.73 \mathrm{~s}$.

3. The maximum load takes place when the ground movement is medium but the reaction between the fluid movement and tank dynamic response is large. For example, T3 stayed stable at the maximum acceleration but overturned at $3.53 \mathrm{~s}$ at a ground acceleration of above $0.11 \mathrm{~g}$. In this respect, higher impulsive modes have a strong effect on the general response of the tank-fluid system.

\section{Bottom sheet uplift}

Figs. 10 and 11 illustrate the vertical uplift time histories of the bottom sheet under the 1940 El Centro and 1994 Northridge earthquakes, respectively. For the tank-fluid system with a fluid height of $6 \mathrm{~m}$, the bottom sheet exhibited no uplift when 
subjected to the earthquakes. However, at a fluid height of $9 \mathrm{~m}$, the bottom sheet uplifted once under the $1940 \mathrm{El}$ Centro earthquake and several times under the 1994 Northridge earthquake. At a fluid height of $12 \mathrm{~m}$, the tank overturned under the $1940 \mathrm{El}$ Centro and 1994 Northridge earthquakes at 3.52 and $4.11 \mathrm{~s}$, respectively. The results show that the tank-fluid system experienced a large uplift when overturning. A comparison of the bottom uplift time histories with the overturning moment time histories suggests that the bottom uplift takes place only when the overturning moment exceeds a specific value. Also, a large bottom uplift happens at a large moment.

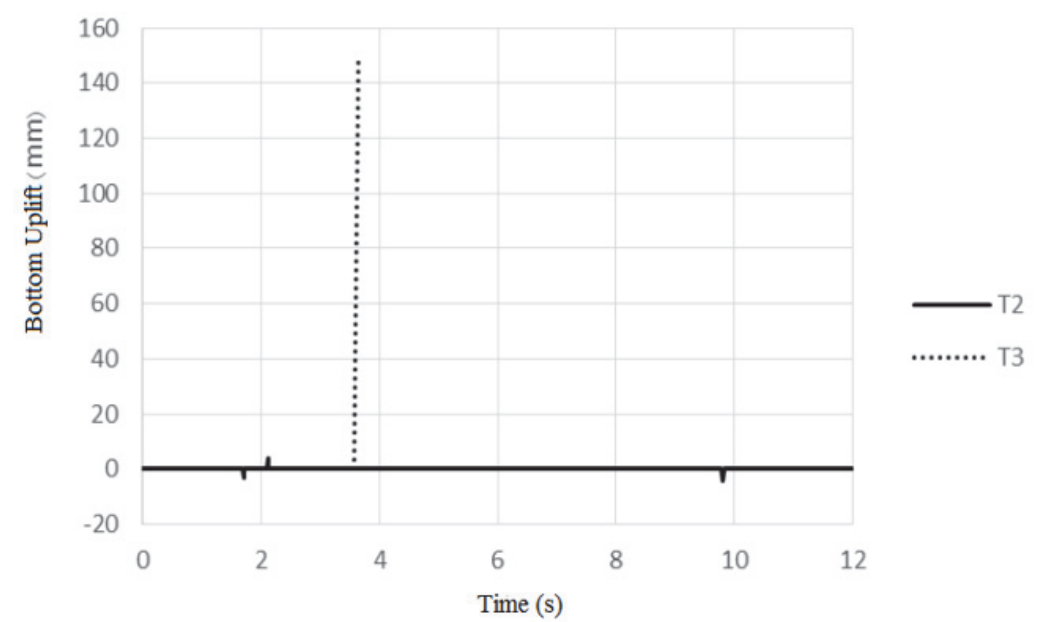

Figure 10: The bottom's uplift time history under the 1940 El Centro earthquake.

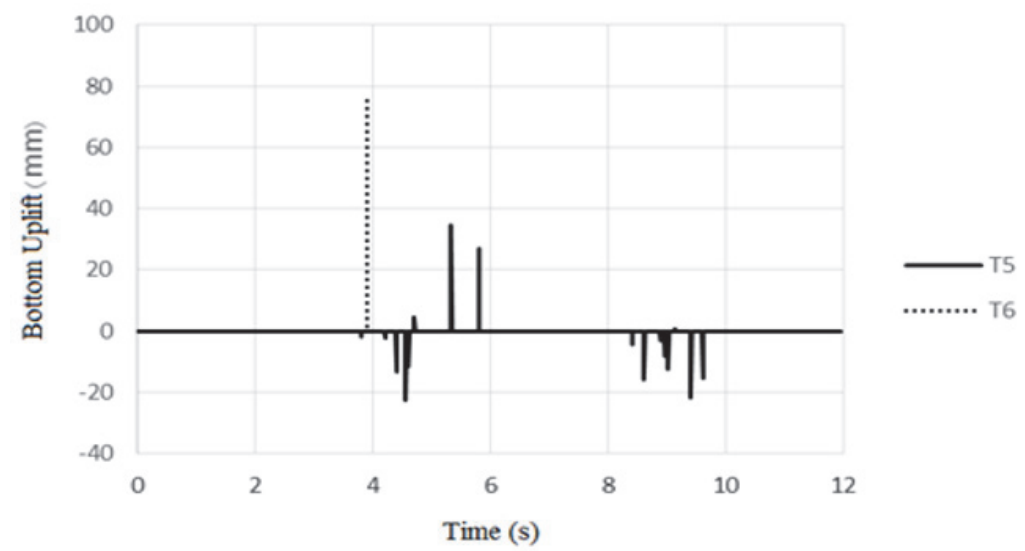

Figure 11: The bottom's uplift time history under the 1994 Northridge earthquake.

As can be seen, there is a clear trend in the bottom uplift rise versus the overturning moment rise in the results. In general, there is a delay between the maximum overturning moment and the maximum bottom uplift. The magnitude and direction of the overturning moment may undergo significant changes in a short period under seismic loads. The time of the overturning moment-induced bottom uplift is typically small. Thus, although the overturning moment is very large, the bottom uplift can remain small. Figs. 9 and 10 present the maximum bottom uplift and the uplifted area. As can be seen, the uplifted area can be more than $9 \%$ of the tank radius. Wozniak et al. [29] provided the ultimate uplift limit.

\section{The wave height within the tank.}

Figs. 12 and 13 demonstrate the wave height time histories at the movement axis $(\theta=0)$ concerning the hydrodynamic pressure on the fluid free surface under the $1940 \mathrm{El}$ Centro and 1994 Northridge earthquakes, respectively. As it can be observed from these figures, the maximum equivalent wave heights under the El Centro earthquake were obtained to be 2.01 and $2.74 \mathrm{~m}$ for T1 and T2, respectively. Also, the maximum equivalent wave heights under the Northridge earthquake were derived to be 3.11 and $5.03 \mathrm{~m}$ for T4 and T5, respectively. Specifically, the assumption of ignorable wave heights does not apply to other analytical models under the same conditions. The results suggest that the fluid wave height can be large and strongly damage upper installations during an earthquake. 


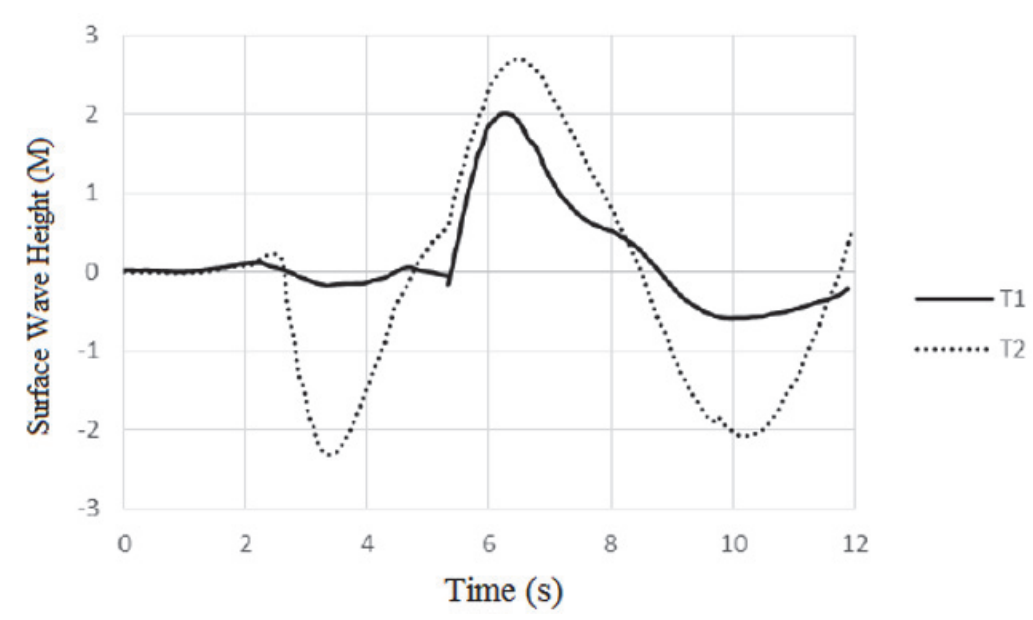

Figure 12: The equivalent wave height time history under the $1940 \mathrm{El}$ Centro earthquake.

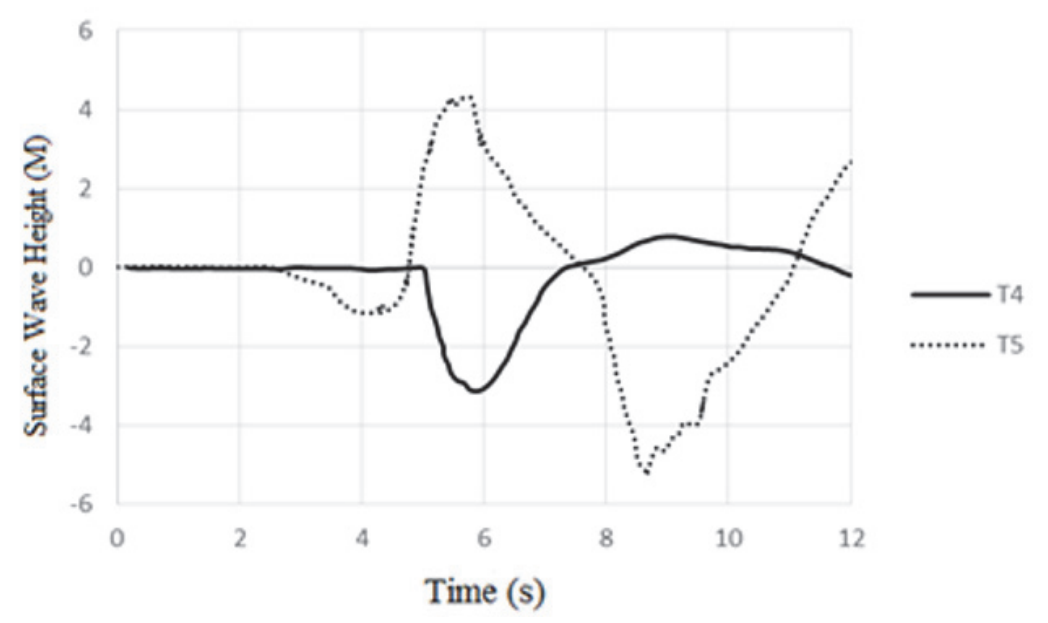

Figure 13: The equivalent wave height time history under the 1994 Northridge earthquake.

The stress and fracture of the tank wall

The stress on the tank wall during an earthquake is generally affected by the membrane mechanism. Figs. 14-17 illustrate the axial stress time histories near the tank bottom and at the middle level of the tank shell at the movement axis $(\theta=0)$. Membrane stress is affected by the overturning moment near the bottom. Membrane stress variations seem to have the same vibration features as the overturning moment near the tank base. At the middle fluid height level, where the overturning moment effect considerably reduces with an increase in the height, the axial stress is influenced by the wall deformation and has a different vibration pattern from the lower of the tank.

As can be seen, the axial stress in the middle of the fluid can be very large. According to Figs. 14 and 16, the axial stress at the bottom of the tank with $6 \mathrm{~m}$ of fluid height is largely affected by the bottom uplift. The tensile stress compared to the compressive stress reduces from 8 to $12 \mathrm{~s}$ in Fig. 8 and from 8 to $11 \mathrm{~s}$ in Fig. 17 for the tank with $9 \mathrm{~m}$ of fluid height due to the El Centro earthquake. The tensile stress may even become compressive stress because of its reduction, which is dependent on the bottom sheet uplift. It is also observed that the maximum axial stress may not happen at the same time as the maximum turnover moment due to the shell deformation effects. The bending mechanism should also be considered both near the tank bottom, where fixes are applied, and in the locations with the highest deformations. The axial stress near the tank bottom is compressive rather than being tensile due to the bottom uplift-induced compression. The circumferential stress, which is generally tensile stress, arises from the outward fluid pressure and shell deformation. On the contrary, the circumferential stress seems to be compressive since the shell is fixed in the radial direction. 


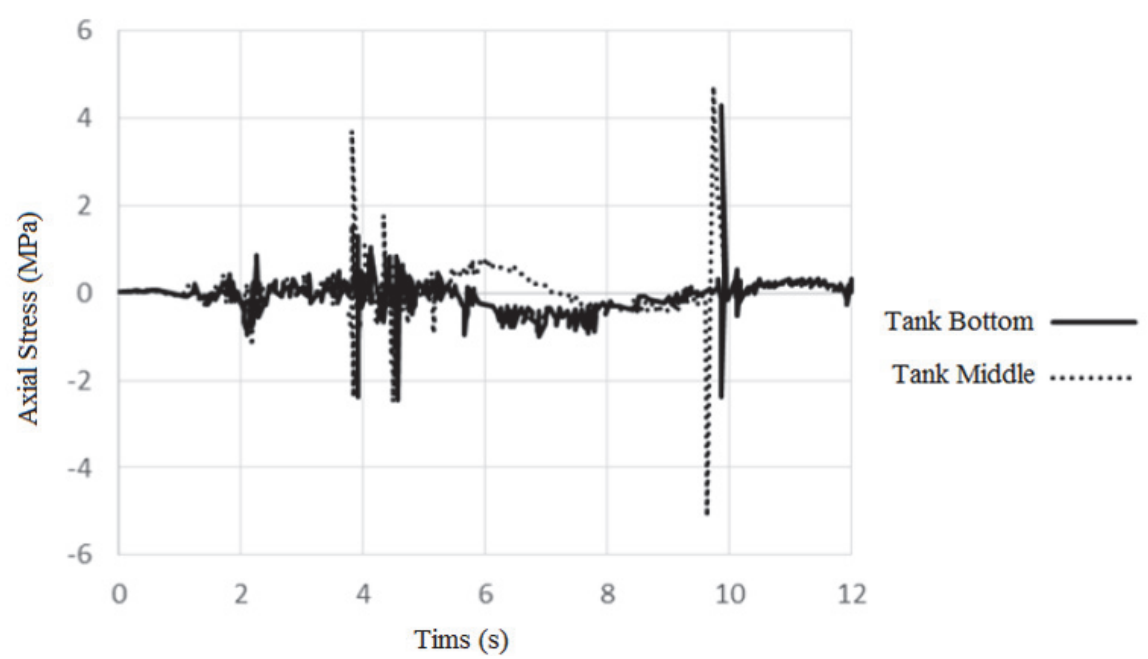

Figure 14: The axial stress time history of T1 under the 1940 El Centro earthquake.

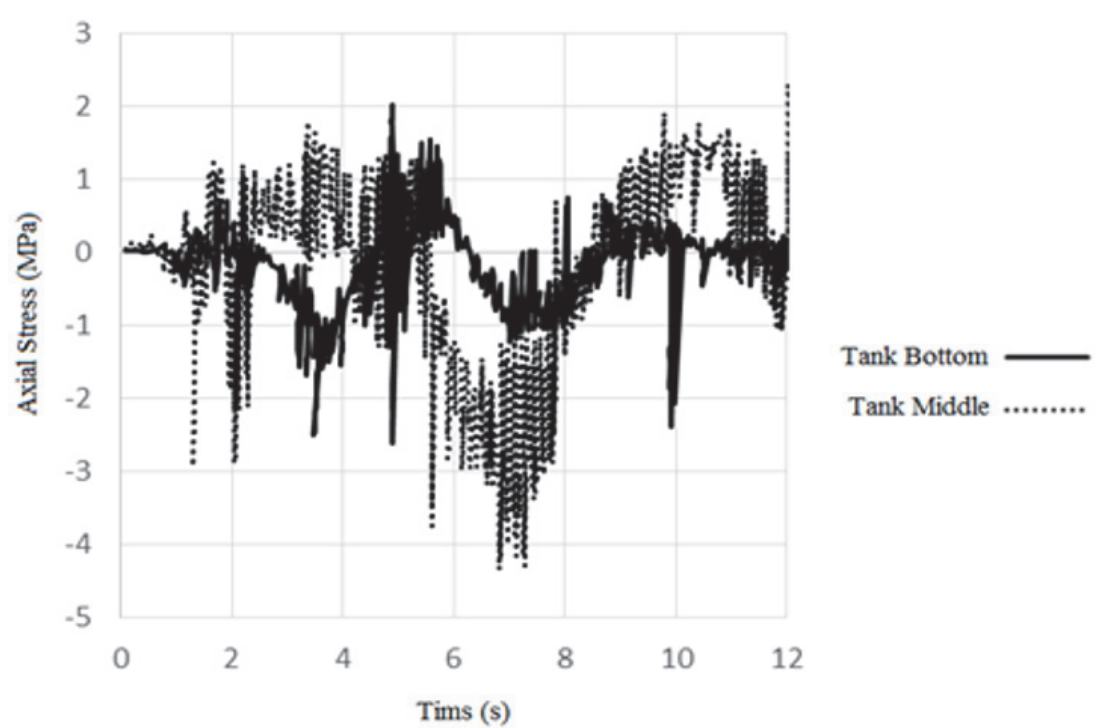

Figure 15: The axial stress time history of T2 under the 1940 El Centro earthquake.

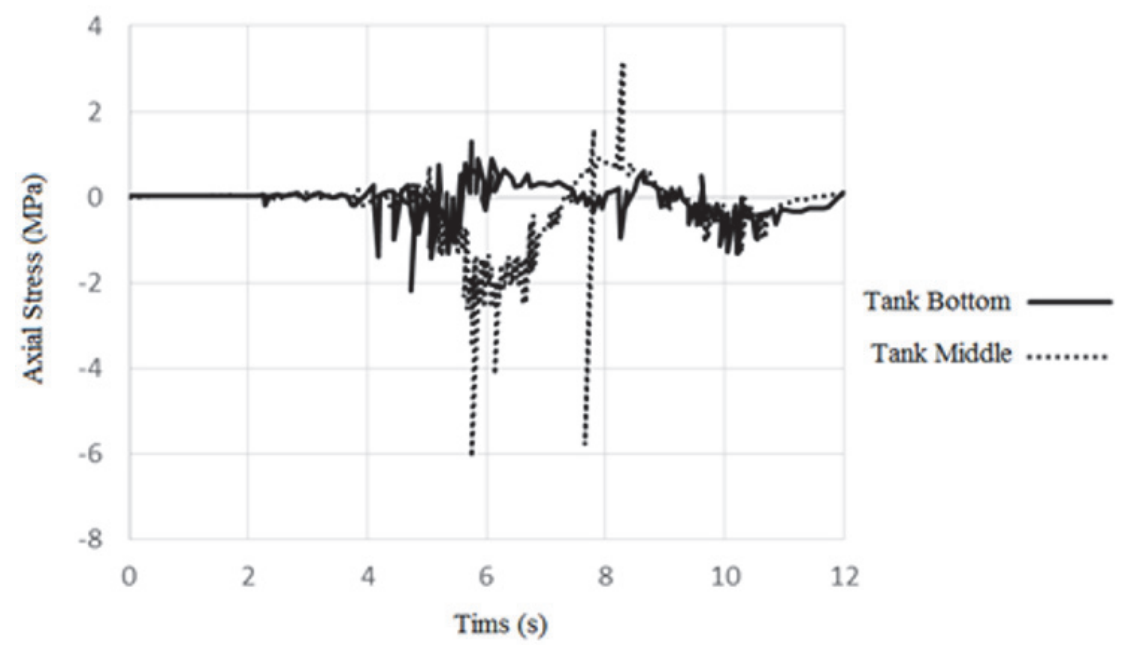

Figure 16: The axial stress time history of T4 under the 1994 Northridge earthquake. 


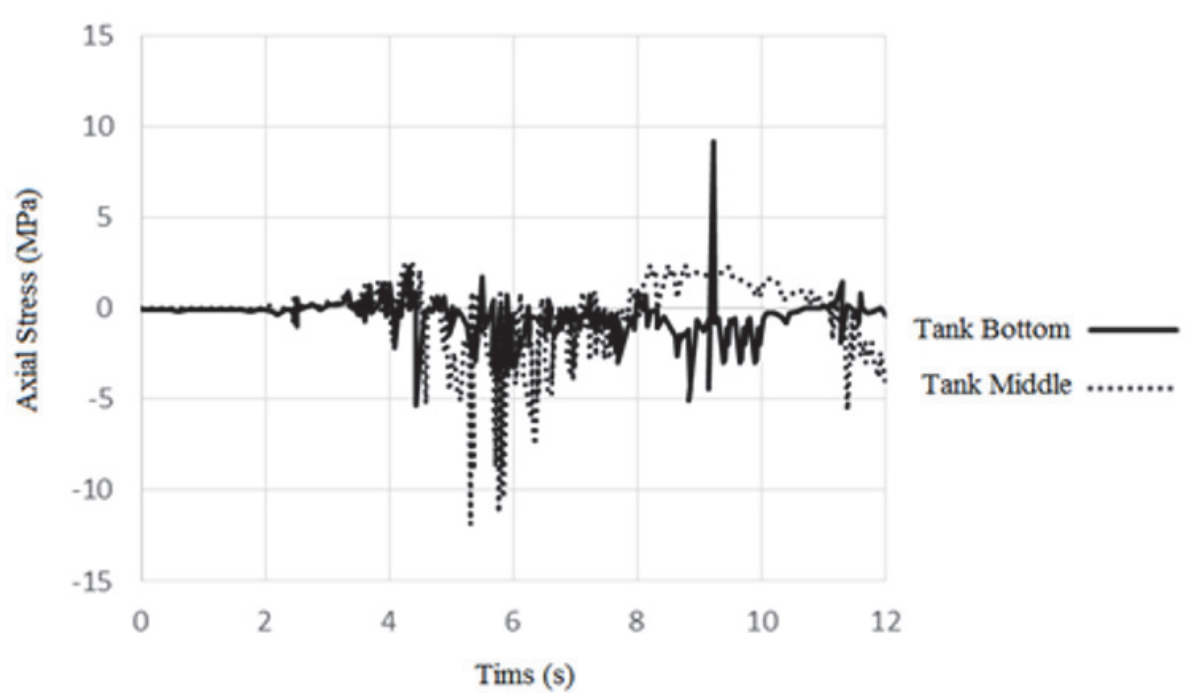

Figure 17: The axial stress time history of T5 under the 1994 Northridge earthquake.

\section{Tank structure failure}

The most-reported seismic damage is the buckling of the tank wall by high stress in response to seismic loads. Tab. 4 provides the highest compressive stress on the tank wall. According to the AWWA D100-96 standard [30], the permissible compressive stress is $105 \mathrm{MPa}$, considering structural stability. According to the analysis results, elephant-foot buckling may happen near the tank base in T2, T3, T5, and T6 due to large compressive stress. Also, elephant-foot buckling can occur on the top of $\mathrm{T} 2$ due to large compressive circumferential stress. In other cases, buckling may take place due to a combination of axial compression and circumferential stress.

Based on the time history analysis results, the dynamic behavior of unanchored steel tanks during an earthquake can be summarized as follows:

A) The dynamic behavior of unanchored systems is the same as that of anchored systems when the seismic load is not large enough to cause bottom uplift. The major deformations of an unanchored tank in response to seismic loads are bottom sheet uplift and out-of-form circular shell deformation due to the lack of anchoring systems. Major tank deformations make the tank-fluid system very flexible.

B) The bottom uplift mechanism is very complicated and nonlinear. The bottom sheet uplifts when the overturning moment exceeds the permissible value. Although there is an alignment between the bottom uplift rise and the overturning moment rise, the bottom uplift behavior varies in wide overturning moment ranges.

C) The lateral loads and the overturning moment may be impulsive or convective, depending on the value and type of the fluid components (i.e., either impulsive or convective).

D) The tank's stress appeared in response to seismic loading is generally influenced by the membrane mechanism. Large bending mechanism-induced stress appear in locations with fixtures and large deformation, particularly in the lower part of the tank.

E) High axial stress may occur near the tank base, leading to elephant-food buckling and the buckling fracture of the wall. A combination of compressive circumferential stress and tensile stress at a high height of a tank may also lead to elephant-foot buckling.

\begin{tabular}{lccc}
\hline Earthquake & $\begin{array}{c}\text { Height } \\
(\mathbf{m})\end{array}$ & $\begin{array}{c}\text { Axial Stress } \\
(\mathbf{k P a})\end{array}$ & $\begin{array}{c}\text { Height } \\
\mathbf{( m )}\end{array}$ \\
1940 El Centro & 6 & 31.4 & 0.46 \\
1940 El Centro & 9 & 109.6 & 0.50 \\
1940 El Centro & 12 & 662.8 & 0.00 \\
1994 Northridge & 6 & 9.2 & 0.38 \\
1994 Northridge & 9 & 160.0 & 0.48 \\
1994 Northridge & 12 & 377.6 & 0.48 \\
\hline
\end{tabular}

Table 4: The maximum stress in the wall of the tank. 


\section{CONCLUSIONS}

7 he numerical model of an unanchored steel ground storage tank demonstrated that the seismic behavior of unanchored tanks in response to seismic loads differs from that of anchored ones due to the nonlinearity of the uplift mechanism. Thus, it is necessary to evaluate the effects of the uplift mechanism when designing a seismic load-resistant tank-fluid system. The effects of the uplift mechanism are generally evaluated by simplified equivalent models due to their complications. However, the results are not reliable. The present study investigated the seismic responses of unanchored tanks by time history analyses. The structural deformation due to uplifts, the interaction between the fluid movement and the dynamic structural response, and tank stress were completely discussed. The major conclusions of this study are outlined as follow:

1. Bottom uplift occurs only when the fluid-induced overturning moment exceeds the critical value;

2. The uplift mechanism is nonlinear to the overturning moment;

3. The uplift mechanism determines the system's dynamic response. The wall sheet turns around the bottom point when the bottom sheet uplifts, which causes larger deformation than the vibration-induced deformation. Tank-fluid systems become very flexible when uplifting.

4. The bottom uplifting mechanism causes large stress on the tank structure. Large compressive stress appears near the bottom and on the top of the shell due to the bottom sheet uplift.

\section{ACKNOWLEDGMENT}

he first author acknowledges the all support from Malayer University when he was an assistant professor of civil engineering from September 2008 to June 2019.

\section{CONFLICT OF INTERESTS}

he authors have no conflict of interest to declare.

\section{REFERENCES}

[1] Jacobsen, L.S. (1949). Impulsive hydrodynamics of fluid inside a cylindrical tank and of fluid surrounding a cylindrical pier. Bull Seismol Soc Amer 39(3), pp. 189204.

[2] Housner, G.W. (1963). The dynamic behavior of water tanks. Bulletin of the Seismological Society of America, 53 (2), pp. 381-387.

[3] Clough, D. P. (1977). Experimental Evaluation of Seismic Design Methods for Broad Cylindrical Tanks. Report No. UC/EERC 77-10. Earthquake Engineering Research Center, University of California, Berkeley, Calif.

[4] Veletsos, A.S. (1974). Seismic effects in flexible liquid storage tanks", Proceedings of Fifth World Conference on Earthquake Engineering, Rome Italy, 1, pp. 630-639

[5] Veletsos, A. S. and Yang, J. Y. (1976). Dynamics of fixed-based liquid storage tanks. Proceedings of 03-Japan Seminar for Earthquake Engineering Research with Emphasis on Lifting systems. Tokyo, pp. 317-341

[6] Veletsos, A. S. and Yang, J. Y. (1977). Earthquake response of liquid storage tanks. Advances in Civil Engineering through Engineering Mechanics Division Specialty Conference, ASCE, North Carolina, pp. 1-24.

[7] Veletsos, A.S. (1984). Seismic response and design of liquid storage tanks. In: Guidelines for the seismic design of oil and gas pipeline systems. ASCE; pp. 255-370. 443-60.

[8] Veletsos, A.S., Tang, Y., and Tang, H.T. (1992). Dynamic response of flexibly supported liquid-storage tanks, Journal of Structural Engineering, ASCE, 118 (1), pp. 264-283. 
[9] Niwa, A. (1978). Seismic Behavior of Tall Liquid-Storage Tanks. Report NO.78, Earthquake Engineering Research Center, University of California at Berkeley.

[10] Niwa, A., Clough, R.W. (1982). Buckling of cylindrical liquid storage tanks under earthquake loading. Earthq Eng Struct Dyn, 10(1), pp. 107_22.

[11] Manos, G.C., Clough, R.W. (1982). Further study of the earthquake response of a broad cylindrical liquid storage tank. Earthquake Engineering Research Center. Report UCB/EERC 82-07.

[12] Zui, H., Osamu, O., Tohru, S., and Akira, N. (1985). Seismic Response Analysis and Dynamic Model Tests of Cylindrical Tanks. Doboku Gakkai Ronbunshu 362, pp. 441-450.

[13] Barton, D. C., and Parker J. V. (1987). Finite element analysis of the seismic response of anchored and unanchored liquid storage tanks." Earthquake engineering \& structural dynamics, 15(3), pp. 299-322.

[14]Chiba, M. (1993). Non-linear hydroelastic vibration of a cantilever cylindrical tank-I. Experiment (empty case). International journal of non-linear mechanics 28(5), pp. 591-599.

[15] Chiba, M. (1993). Non-linear hydroelastic vibration of a cantilever cylindrical tank-II. Experiment (liquid-filled case). International journal of non-linear mechanics 28(5), pp. 601-612.

[16] El-Zeiny, A. (1995). Nonlinear time-dependent seismic response of unanchored liquid storage tanks. Ph.D. dissertation. Irvine: Department of Civil and Environmental Engineering, University of California.

[17] Malhotra, P.K., Veletsos, A.S. (1994). Beam model for the base-uplifting analysis of cylindrical tanks. J Struct Eng, ASCE 120(12), pp. 3471-3488.

[18] Malhotra, P.K. (1995). Base uplifting analysis of flexibly supported liquid-storage tanks. Earthq Eng Struct Dyn 24(12), pp. 1591-1607.

[19] Malhotra, P.K. (1997). Seismic response of soil-supported unanchored liquid storage tanks. Journal of Structural Engineering, ASCE, 123 (4), pp. 440-450.

[20] Malhotra, P.K. (2000). Simple procedure for seismic analysis of liquid-storage tanks. Structural Engineering International, 3, pp. 197-201.

[21] Souli, M., Zolesio J.P. (2001). Arbitrary Lagrangian_Eulerian and free surface methods in fluids mechanics. Comput Methods Appl Mech Eng 191, pp. 451-466.

[22] Taniguchi, T. (2004). Rocking behavior of unanchored flat-bottom cylindrical shell tanks under the action of horizontal base excitation. Eng Struct 26, pp. 415-426.

[23] Aquelet, N., Souli, M., Olovsson, L. (2006). Euler-Lagrange coupling with damping effects: Application to slamming problems. Computer methods in applied mechanics and engineering. 195(1-3), pp. 110-32.

[24] Virella, J.C., Godoy, L.A., Suarez, L.E. (2006). Dynamic buckling of anchored steel tanks subjected to horizontal earthquake excitation. J Constr Steel Res 62, pp. 521-531.

[25] Maekawa, A., Shimizu, Y., Suzuki, M. and Fujita, K. (2010). Vibration Test of a 1/10 Reduced Scale Model of Cylindrical Water Storage Tank, Journal of Pressure Vessel Technology, 132(5), 051801-1-051801-13.

[26] Maekawa, A. (2012). Consideration of a method to estimate seismic response reduction coefficient for liquid storage tanks.,15th WCEE, LISBOA.

[27] Maekawa, A. (2013). Recent Advances in Seismic Response Analysis of Cylindrical Liquid Storage Tanks, Institute of Nuclear Safety System, Inc. Japan, 2(12).

[28] Pacific Earthquake Engineering Research Center, PEER Strong Motion Database, (2011) http://peer.berkley.edu.smcat.

[29] Wozniak, R. S., and Warren, W. (1978). Basis of seismic design provisions for welded steel oil storage tanks. Chicago Bridge \& Iron Company.

[30] American Water Works Association. Standard for welded steel tanks for water storage. ANSI/AWWA D100-96 (1997). 